\title{
Tribological Characteristics Improvement of Wear Resistant MAO-Coatings
}

\author{
V. N. Malyshev, A. M. Volkhin, and B. M. Gantimirov \\ Gubkin Russian State University of Oil and Gas, 65 Leninsky Prospect, Moscow 119991, Russia \\ Correspondence should be addressed to V. N. Malyshev; vmal@inbox.ru
}

Received 24 March 2013; Accepted 3 June 2013

Academic Editor: Fahmina Zafar

Copyright ( 2013 V. N. Malyshev et al. This is an open access article distributed under the Creative Commons Attribution License, which permits unrestricted use, distribution, and reproduction in any medium, provided the original work is properly cited.

Currently, the most promising technology of coating formation is microarc oxidation (MAO) with unique properties of the surface layer, which combine high wear resistance, corrosion resistance, and heat and erosion resistance. Microarc oxidation can be used for parts and components manufacturing in various segments of industries. However, the technology improvement by improving the tribological characteristics of MAO-coatings can not only enhance economic effect, but also expand its application.

\section{Introduction}

Microarc oxidation (MAO) method was achieved in the early 1970 s of the 20 th century as the result of discovering microarc discharges phenomenon in electrolyte by Markov in the Institute of Inorganic Chemistry $[1,2]$. This is quite a new method of improving the surface strength. Coatings with high wear resistance and high adhesive strength to base material can be achieved by this method.

The essence of the method is the collaboration of electrochemical oxidation and electrodischarges phenomena at the anode-electrolyte border. The term "microarc oxidation" means electrochemical oxidation of the anode (or detail part) under the voltage higher than the voltage of sparking.

The most important advantages of the method include

(i) coating deposition without any pretreatment (grinding, degreasing, pickling, etc.), which significantly reduces the cost and complexity of work;

(ii) the possibility of coating figurine details (including internal and threaded surfaces, hidden cavities);

(iii) coating formation with thickness from 0.05 to $0.2 \mathrm{~mm}$ and 0.3 to $1.0 \mathrm{~mm}$ and adhesion, comparable to the strength of the base material;

(iv) significant oxidation process time reduction (2-2.5 times) in comparison with thick anodizing;

(v) the possibility of full process automation; (vi) cheapness and availability of reagents and materials;

(vii) wide range of process speed regulations;

(viii) environmental friendliness of the process (does not require the use of special sewage treatment plants).

Microarc oxidation is mainly used for valve metals. The composition of MAO-coatings is a complex of aluminum oxides, including high-temperature phase $\left(\alpha-\mathrm{Al}_{2} \mathrm{O}_{3}\right)$ as well as element compounds which are included in the base material and the electrolyte.

Today, ceramic coatings are widely used on aluminum alloys. The driving force behind this has been the high chemical affinity for oxygen and the unique properties of $\mathrm{Al}_{2} \mathrm{O}_{3}$ oxide. Among the positive qualities of aluminum alloys, their lightness, high relative strength, high corrosion resistance, cold resistance, good weld ability, and high manufacturability should be noted. Besides, aluminum alloys are nonmagnetic and are characterized by the absence of sparking under friction conditions.

Microarc oxidation (also known as plasma electrolytic oxidation $[3,4]$ ) is now widely used in various industriesfrom medicine to aerospace, including oil and gas industry.

Today, however, deeper formations study of MAOcoating is needed from the position of taking into account the diversity of their forms and the nonlinear properties dependence on the structure and composition. Also, a detailed study about various technological factors influence on the 
properties of MAO-coatings is required. Therefore, one of the promising areas of research with a view to enhance the method is to improve the tribological properties of MAOcoatings.

\section{Materials and Methods}

It is known that microarc oxidation can be an anode, a cathode, and an anodic-cathodic $[5,6]$. Anode MAO method allows to form the coating on the anode surface, which can be used as decorative, corrosion-resistant, heat-resistant, and insulating coatings, but not as high wear resistant because of the relatively high porosity and insufficient coating adhesion to the substrate. Current characteristics of the cathode method discharges exceed maximum anode discharges by 5-10 times. But in most cases, the appearance of cathode discharges does not lead to quality coatings with good adhesion and strength because microarcs are not able to coat the cathode without a certain additional condition. Anodiccathodic method is the best formation technology of such coatings because of difference in the formation mechanism of the surface layer.

2.1. Anodic-Cathodic MAO Method. During the process of anodic-cathodic MAO method electric discharges arise under the positive (anode) and negative (cathode) voltage pulses. The presence of two discharge types allows to carry out complex electrochemical processes and to change modes in a wide range. This makes it possible to form coatings of various composition and structure. At that, operations of etching, degreasing, bleaching, filling, and flushing the sample surface are not necessary.

In addition, the method is different in having smaller amount of equipment used for oxidation and reduced consumption of chemicals, nontoxic, and volatile chemical compounds which are traditionally used.

Studies of coatings formed by anodic-cathodic microarc oxidation revealed their high hardness, wear resistance, adhesion, and the ability to use as a tribological material in various fields of engineering [5-7].

The capacity of microdischarges (current density) and the electrolyte significantly affect the coating porosity. The most dense coatings with lower porosity can be received under the minimum values of the current density. This rule is based on the fact that microarc discharges break through oxide film which is on the surface of the metal and then melt the film and the local volume of the base metal.

In the presence of an oxidizing environment new compounds with a rapid cooling of the reaction products appear. The higher the energy of microarc through break the larger the surface crystals and the greater distance between discharges. It obviously leads to increasing the number of pores. "Craters" from the powerful arcs can be formed on the surface by a significant current density increasing $\left(>30 \mathrm{~A} / \mathrm{dm}^{2}\right)$.

Thus, the coating obtained by this method consists of two layers: the outermost-porous, relatively soft and the innermost-dense, of better adhesion strength, and virtually nonporous. The outer layer which is from 10 to $30 \%$ of the coating thickness is usually porous and has to be removed by diamond grinding.

All experimental coatings were formed under the typical conditions for the anodic-cathodic method. The electrolyte composition and characteristics of the process were selected on the basis of optimal technological modes for coatings with high wear resistance and minimal porosity.

MAO-coating was formed on the prepared "block" samples $10 \times 10 \times 10 \mathrm{~mm}$ in size from aluminum alloy 2024 (D16) system $\mathrm{Al}-\mathrm{Cu}-\mathrm{Mg}$ for further tribological properties testing on the friction machine SMC-2. This aluminum alloy was chosen because of its wide use in petroleum, oil and gas and petrochemical industries. Its application is caused by properties which compete with steel and other materials.

The samples were immersed in the bath with slightly alkaline electrolyte (KOH $2 \mathrm{~g} / \mathrm{l})$ supplemented with sodium silicate $\left(\mathrm{Na}_{2} \mathrm{SiO}_{3} 2 \mathrm{~g} / \mathrm{l}\right)$ and sodium hexametaphosphate $\left(\mathrm{Na}_{6} \mathrm{P}_{6} \mathrm{O}_{18} 2 \mathrm{~g} / \mathrm{l}\right)$. The process was conducted in the anodiccathode mode at the anodic voltage up to $600 \mathrm{~V}$ and at the cathode voltage up to $190 \mathrm{~V}$ during 25 minutes. The current density did not exceed $30 \mathrm{~A} / \mathrm{dm}^{2}$. At such mode of formation, the coating deepens into the metal, and the sample size is changed not more than $10 \%$ of the formed film thickness. After completion of the oxidation, the samples were taken from the bath, washed, and dried at room temperature. Thus, after microarc processing, the MAO-coating thickness was 90-100 microns.

The electrolyte temperature was kept constant by a cooling bath with running water during the oxidation process. Electrolyte mixing was made by compressed air bubbling with compressor.

2.2. Polymer Filling of Surface. Filling of MAO-coatings surface layer was carried out by the polymer on the preformed MAO sample surface using slip method. Towards this, the MAO coated sample was placed in a preheated to a temperature of $240-245^{\circ} \mathrm{C}$ kiln. When the polymer reached its melting point, it had evenly spread over the surface, filling all pores and asperities. After cooling, polymer had "vitrified" and formed a smooth, transparent layer with dense surface.

The samples were kept in the kiln until the polymer had melted, sintered, and formed a film. Then they were exposed to the air, where the polymer layer crystallization took place at room temperature. The thickness of the polymer layer was 50-70 microns.

2.3. Improvement of the MAO Method. In Gubkin Russian State University of Oil and Gas, the authors of this paper carried out the scientific work on the theme of tribological characteristics improvement of the coatings formed on the basis of the anodic-cathode MAO method. This work involves the selection of material for an extra protective layer for MAO-coating, the method of its application, and the experiments for friction coefficient determination of composite coatings.

Ultrahigh molecular weight polyethylene (UHMWPE) was chosen as a coating material for impregnation of the surface layer. UHMWPE has properties best suited to create a 
TABLE 1: Key characteristics of some polymer materials.

\begin{tabular}{lcccc}
\hline Polymer & $\begin{array}{c}\text { Density } \\
\mathrm{kg} / \mathrm{m}^{3}\end{array}$ & $\begin{array}{c}\text { Hardness } \\
\mathrm{MPa}\end{array}$ & $\begin{array}{c}\text { Wear resistance on quarz sand } \\
\mathrm{min} / \mathrm{mm}^{3}\end{array}$ & $\begin{array}{c}\text { Friction coefficient } \\
-\end{array}$ \\
\hline UHMWPE & $\mathbf{9 3 4}$ & $\mathbf{4 0}$ & $\mathbf{1 8 , 4 0}$ & $\mathbf{0 , 0 8}$ \\
UHMWPE $+\mathrm{MoS}_{2}$ & 1150 & 55 & 31,60 & 0,10 \\
PELP (low pressure) & 950 & 55 & 2,79 & 0,27 \\
PEHP (high pressure) & 900 & 28 & 2,08 & 0,35 \\
Polypropylene & 850 & 51 & 6,36 & - \\
Teflon-4 & 2130 & 38 & 5,46 & 0,05 \\
Teflon-3 & 2160 & 130 & 0,93 & 0,45 \\
Polystyrene & 1040 & 175 & 1,30 & 0,55 \\
Polymethylmethacrylate & 1170 & 181 & 12,90 & 0,22 \\
Polyamide resin & 1080 & 109 & 3,38 & 0,23 \\
Kaprolone & 1130 & 180 & 3,64 & 0,58 \\
Vinyl & 1420 & 122 & 2,47 & 0,60 \\
Polycarbonate & 1180 & 101 & 1,56 & 0,13 \\
Polyacetal & 1390 & 177 & 1,64 & - \\
Epoxy resin & 1270 & 202 & 1,30 & - \\
Wood plastic & 1260 & 312 & 0,82 & - \\
Fiberglass AГ-43 & 1850 & 369 & & - \\
\hline
\end{tabular}

Note: Wear resistance was taken as the quantity opposite value to the rate of wear.

modified additional and protective layer in comparison with other polymers. Main advantages of UHMWPE are

(i) high strength;

(ii) high resistance to impact and cracking;

(iii) high antifriction properties close to the properties of PTFE (Teflon) and polyamide (nylon);

(iv) low friction coefficient equal to PTFE (Teflon) and polyamide (nylon);

(v) high wear resistance in comparison with other polymers;

(vi) the ability to keep the mechanical properties over a wide temperature range from -269 to $120^{\circ} \mathrm{C}$;

(vii) high chemical resistance.

Comparative characteristics of polymer materials [8] are given in Table 1.

The use of this covering method allowed us to avoid the application of labor-intensive operations, surface preparation for coating: sandblasting, gritblasting, and other methods of mechanical surface cleaning to ensure adhesion of the polymer to the metal. It is not necessary to abrasive blast clean the sample surface, because after microarc oxidation the sample has a quite rough and porous surface, which provides high adhesion of the polymer to the MAO-coating.

2.4. Experimental Tests on Friction and Wear. Tribological tests of samples were carried out on friction machine type SMC-2 on friction scheme "block-roller" under conditions of unidirectional slide in industrial water. Linear sliding speed was $0.9 \mathrm{~m} / \mathrm{s}$ (for rollers $\varnothing 35 \mathrm{~mm}$ ) and $1.3 \mathrm{~m} / \mathrm{s}$ (for rollers $\varnothing 50 \mathrm{~mm}$ ) with an initial unit load $20 \mathrm{~kg} / \mathrm{cm}^{2}$, followed by (after $10000 \mathrm{rpm}$ ) increasing loads up to $50 \mathrm{~kg} / \mathrm{cm}^{2}$ for some samples and up to $100 \mathrm{~kg} / \mathrm{cm}^{2}$ for others. Friction coefficients for pairs of friction "block-roller" were determined. The "blocks" were produced using the proposed technology. The counterparts (rollers) were made from steel $420 S 45$ (X38Cr13).

\section{Results and Discussion}

At present, both Russian $[7,9,10]$ and foreign scientists [11, 12] pay a lot of attention to the study of MAO-coatings porosity. The fact is that the value of porosity significantly affects the physical, mechanical, and tribological properties of coating. At high quantity of pores, the basic physical and mechanical properties of the coating (HV, E, and others) are reduced. Porosity also affects permissible amount of the specific load.

In such a way, improvement of the tribological properties of MAO-coatings is becoming the actual goal of achieving the minimum porosity coatings, in particular, by choosing the optimal modes of formation process as well as the use of special additional treatment.

The problem solution in this area can be achieved by improving the MAO method and applying the special treatment, which consists in impregnating the surface layer of the various components or applying an extra layer of protective material.

In the study of antifriction properties of the samples, start time of the test was recorded. And after 10,000 circles weight loss was measured with an increase of the specific load. The friction path of samples was $1099 \mathrm{~m}$ (at a speed of $0.9 \mathrm{~m} / \mathrm{s}$ ) and $1578 \mathrm{~m}$ (at a speed of $1.3 \mathrm{~m} / \mathrm{s}$ ), respectively. The friction coefficient was recorded during the experiment, and then the average value was calculated. 
TABLE 2: Tribological characteristics of MAO-coatings and MAO + UHMWPE coatings.

\begin{tabular}{|c|c|c|c|c|c|c|c|c|c|c|c|}
\hline \multirow{3}{*}{$\begin{array}{l}\text { Number of } \\
\text { tests }\end{array}$} & \multirow{3}{*}{ Coating } & \multirow{3}{*}{$\begin{array}{c}\text { Linear } \\
\text { speed, m/s }\end{array}$} & \multicolumn{3}{|c|}{ Specific load $20 \mathrm{~kg} / \mathrm{cm}^{2}$} & \multicolumn{3}{|c|}{ Specific load $50 \mathrm{~kg} / \mathrm{cm}^{2}$} & \multicolumn{3}{|c|}{ Specific load $100 \mathrm{~kg} / \mathrm{cm}^{2}$} \\
\hline & & & \multirow{2}{*}{$f_{\text {fr }}$} & \multicolumn{2}{|c|}{ Wear rate, g/h } & \multirow{2}{*}{$f_{\text {fr }}$} & \multicolumn{2}{|c|}{ Wear rate, $\mathrm{g} / \mathrm{h}$} & \multirow{2}{*}{$f_{\text {fr }}$} & \multicolumn{2}{|c|}{ Wear rate, $g / h$} \\
\hline & & & & block & roller & & block & roller & & block & roller \\
\hline \multirow{2}{*}{1} & MAO & \multirow[b]{2}{*}{0,9} & 0,315 & 0,013 & 0,009 & 0,378 & 0,031 & 0,026 & - & - & - \\
\hline & $\begin{array}{l}\mathrm{MAO}+ \\
\mathrm{UHMWPE}\end{array}$ & & 0,128 & 0,012 & 0,011 & 0,207 & 0,012 & 0,011 & - & - & - \\
\hline \multirow[t]{2}{*}{2} & MAO & \multirow{2}{*}{0,9} & 0,232 & 0,078 & 0,009 & - & - & - & \multicolumn{3}{|c|}{$\begin{array}{l}\text { unstable friction, galling, significant } \\
\text { Wear of roller }\end{array}$} \\
\hline & $\begin{array}{c}\text { MAO + } \\
\text { UHMWPE }\end{array}$ & & 0,074 & 0,023 & 0,011 & - & - & - & 0,244 & 0,017 & 0,002 \\
\hline \multirow{2}{*}{3} & $\mathrm{MAO}$ & \multirow[b]{2}{*}{0,9} & 0,225 & 0,012 & 0,015 & 0,236 & 0,029 & 0,018 & 0,194 & 0,031 & 0,015 \\
\hline & $\begin{array}{c}\mathrm{MAO}+ \\
\mathrm{UHMWPE}\end{array}$ & & - & - & - & - & - & - & 0,044 & 0,015 & 0,008 \\
\hline \multirow{2}{*}{4} & MAO & \multirow[b]{2}{*}{0,9} & 0,253 & 0,007 & 0,018 & 0,361 & 0,011 & 0,032 & - & - & - \\
\hline & $\begin{array}{c}\mathrm{MAO}+ \\
\mathrm{UHMWPE}\end{array}$ & & 0,109 & 0,009 & 0,018 & 0,208 & 0,010 & 0,011 & - & - & - \\
\hline \multirow{2}{*}{5} & MAO & \multirow[b]{2}{*}{0,9} & 0,346 & no & 0,017 & 0,325 & 0,006 & 0,005 & - & - & - \\
\hline & $\begin{array}{c}\text { MAO + } \\
\text { UHMWPE }\end{array}$ & & 0,106 & 0,027 & 0,004 & 0,094 & 0,031 & 0,021 & - & - & - \\
\hline \multirow{2}{*}{6} & MAO & \multirow[b]{2}{*}{1,3} & 0,394 & no & 0,046 & 0,482 & 0,023 & 0,073 & - & - & - \\
\hline & $\begin{array}{l}\mathrm{MAO}+ \\
\mathrm{UHMWPE}\end{array}$ & & 0,028 & 0,006 & 0,009 & 0,183 & 0,002 & 0,035 & - & - & - \\
\hline
\end{tabular}

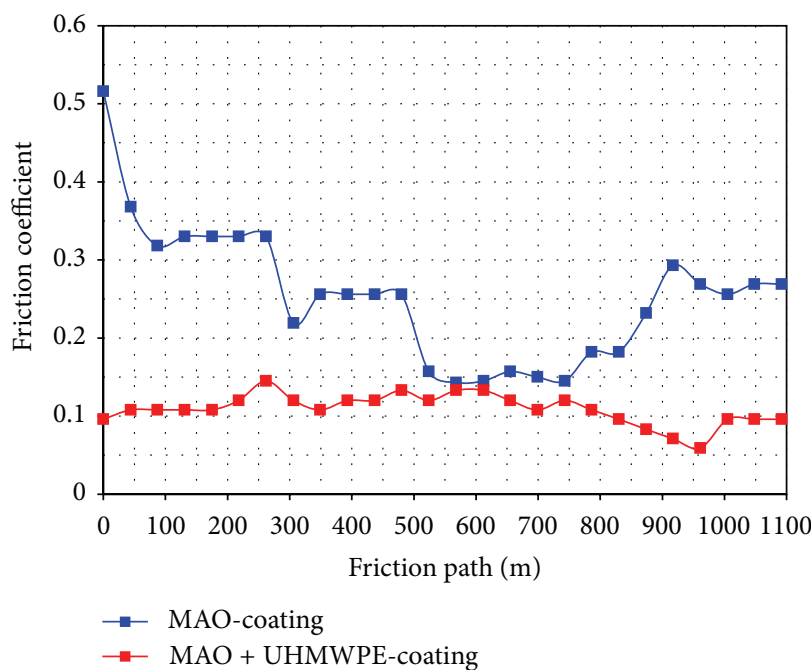

(a)

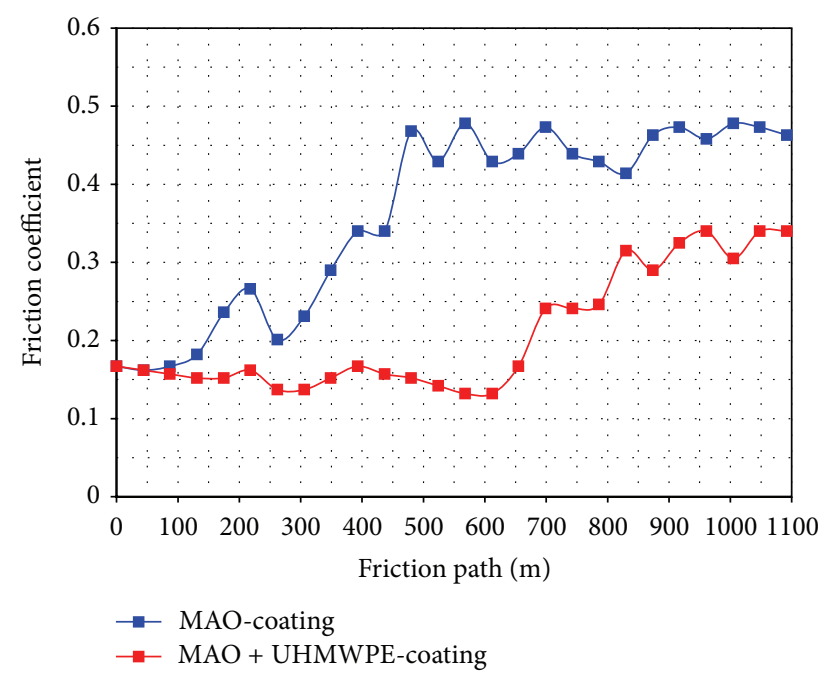

(b)

FIGURE 1: Dependences of the friction coefficient for samples with MAO-coating and MAO + UHMWPE coating during the experiment at a specific load of $20 \mathrm{~kg} / \mathrm{cm}^{2}$ (a) and $50 \mathrm{~kg} / \mathrm{cm}^{2}$ (b).

Table 2 shows the numerical values of the friction coefficient and wear rate, depending on the specific load for specimens with traditional MAO-coatings and the coatings produced by the proposed method (MAO-coating with a layer of UHMWPE).

3.1. Impregnation Influence on Tribological Properties of MAOCoatings. The test results (see Figures 1 and 2) suggest that the use of additional treatment (impregnation with UHMWPE) increases the wear resistance of MAO-coatings and improves its antifriction properties.

Reduction of friction coefficient $\left(f_{\text {fr }}\right)$ under load of $20 \mathrm{~kg} / \mathrm{cm}^{2}$ is almost $70 \%$ and about $45 \%$ at $50 \mathrm{~kg} / \mathrm{cm}^{2} \mathrm{load}$. At a specific load of $100 \mathrm{~kg} / \mathrm{cm}^{2}$, samples, made by the recommended technology, showed good results and relatively low rate of wear of the sample and counterpart, as opposed to samples without polymer layer. In some cases, especially with a high specific load $\left(100 \mathrm{~kg} / \mathrm{cm}^{2}\right)$, this led to the seizure of the friction pair (see experiment number 2 in Table 2). 


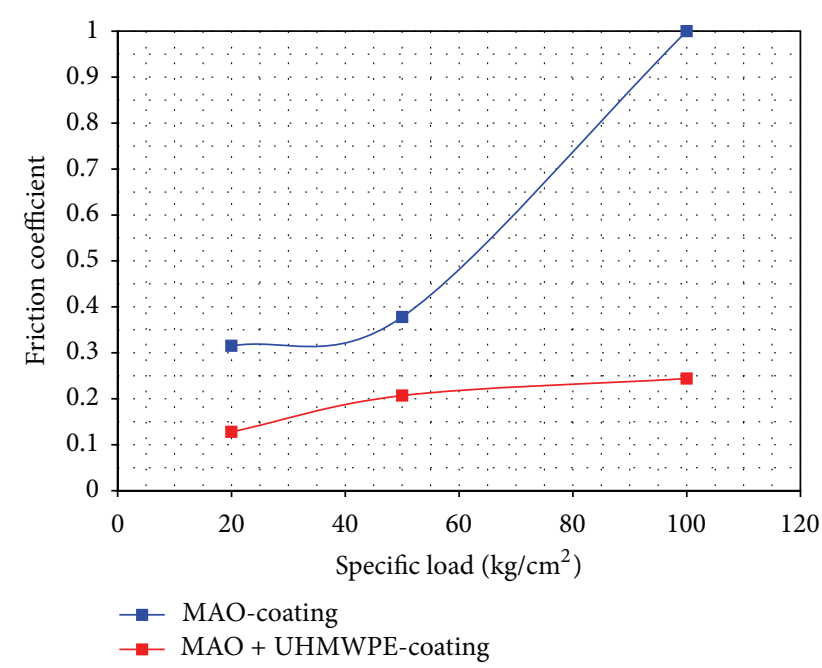

FIGURE 2: Friction coefficient dependence on the specific load of the samples with MAO-coating and MAO + UHMWPE coating.

The received experimental data will allow improving working surfaces of friction details for some kind of oil and gas equipment (for the production of wear resistant balls and seals for ball valves and O-rings for piston pumps) and many others.

\section{Conclusions}

As a result of research work, the samples with the modified MAO-coatings which have high anti-friction properties were obtained. The experiments confirmed that an additional layer of UHMWPE contribute to the impregnation of the surface layer of MAO-coating and improves its tribological characteristics. The outer polymer layer increases the service life of the coating and creates the effect of "self-lubricating" the friction pair under conditions without lubricant.

The proposed composite coating "MAO + UHMWPE" also exhibits a synergistic effect, characterized by that the effectiveness of new coating is much greater than the effect of the "simple sum" of the individual properties of MAO-coating and UHMWPE.

\section{References}

[1] Microarc Oxidation, The Science and Humanity, Znanie, Moscow, Russia, 1981.

[2] G. A. Markov, V. I. Belevantsev, O. P. Terleeva, E. K. Shulepko, and A. I. Slonova, "Microarc oxidation," Vestnik Mashinostroeniya, vol. 1, series 6, p. 34, 1992.

[3] A. L. Yerokhin, X. Nie, A. Leyland, A. Matthews, and S. J. Dowey, "Plasma electrolysis for surface engineering," Surface and Coatings Technology, vol. 122, no. 2-3, pp. 73-93, 1999.

[4] A. L. Yerokhin, L. O. Snizhko, N. L. Gurevina, A. Leyland, A. Pilkington, and A. Matthews, "Discharge characterization in plasma electrolytic oxidation of aluminium," Journal of Physics D, vol. 36, no. 17, pp. 2110-2120, 2003.

[5] A. A. Petrosyants, V. N. Malyshev, V. A. Fedorov, and G. A. Markov, "Wear kinetics of coatings deposited by microarc oxidation," Trenie i Iznos, vol. 5, no. 2, pp. 127-130, 1984 (Russian).

[6] V. N. Malyshev, "Coating formation by anodic-cathodic microarc oxidation," Zashchita Metallov, vol. 32, no. 6, pp. 662667, 1996 (Russian).

[7] V. N. Malyschev, "Mikrolichtbogen-Oxidation-ein neuartiges Verfahren zur Verfestigung von Aluminiumoberflaechen," Metalloberflaech, no. 8, pp. S606-S608, 1995.

[8] I. N. Andreeva, E. V. Veselovskaya, E. I. Nalivayko, A. D. Pechenkin, V. I. Buchgalter, and A. V. Polyakov, "Ultrahigh molecular weight polyethylene with high density," L: Chimia, p. 40, 1982 (Russian).

[9] V. N. Malyshev, "Neue Anwendungsmoeglichkeiten fuer Aluminium," Metalloberflaeche, no. 1-2, pp. S28-S29, 2006.

[10] S. V. Gnedenkov, O. A. Khrisanfova, A. G. Zavidnaya et al., "Production of hard and heat-resistant coatings on aluminium using a plasma micro-discharge," Surface and Coatings Technology, vol. 123, no. 1, pp. 24-28, 2000.

[11] G. Sundararajan and L. Rama Krishna, "Mechanisms underlying the formation of thick alumina coatings through the MAOcoating technology," Surface and Coatings Technology, vol. 167, no. 2-3, pp. 269-277, 2003.

[12] J. A. Curran and T. W. Clyne, "Porosity in plasma electrolytic oxide coatings," Acta Materialia, vol. 54, no. 7, pp. 1985-1993, 2006. 

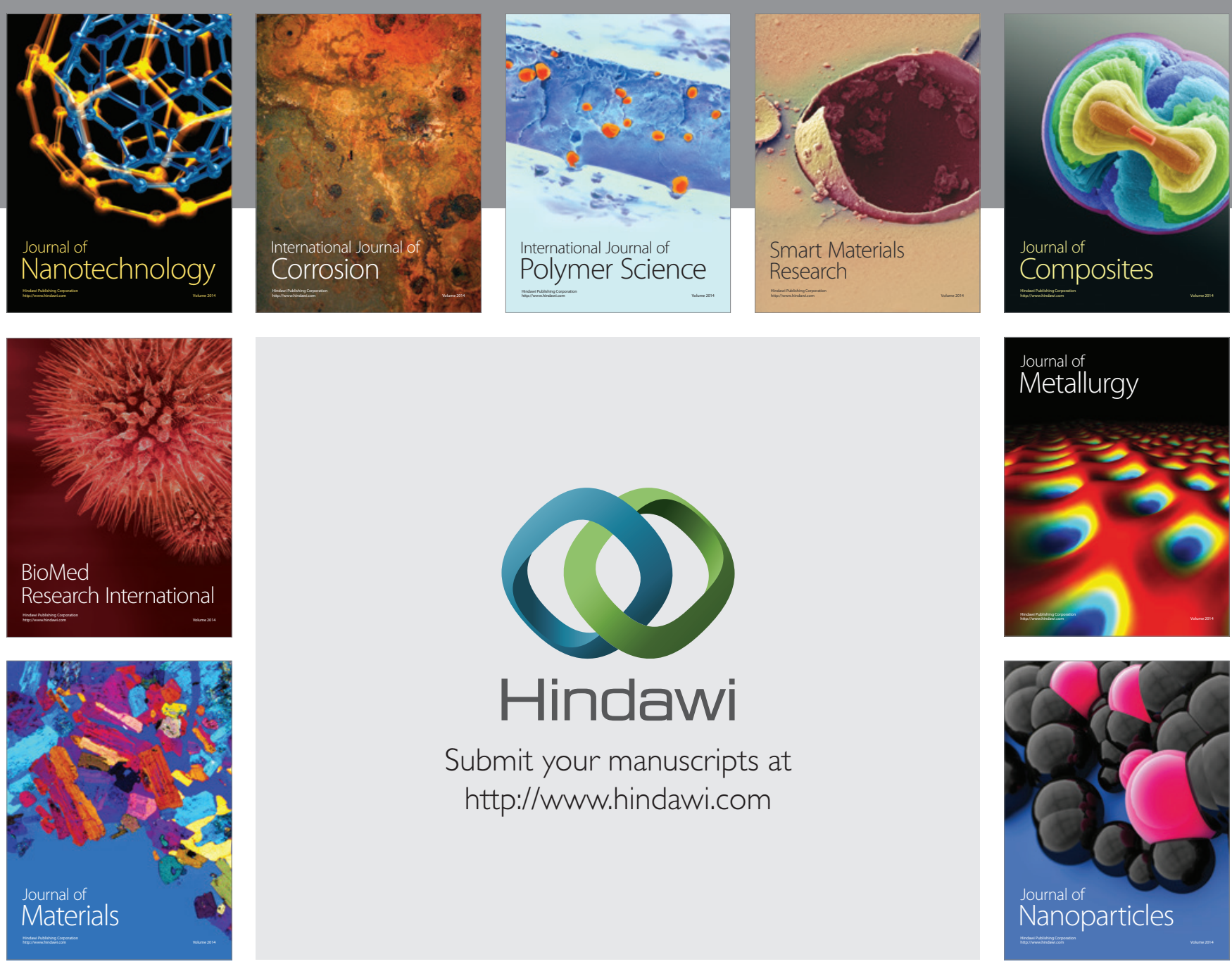

Submit your manuscripts at http://www.hindawi.com
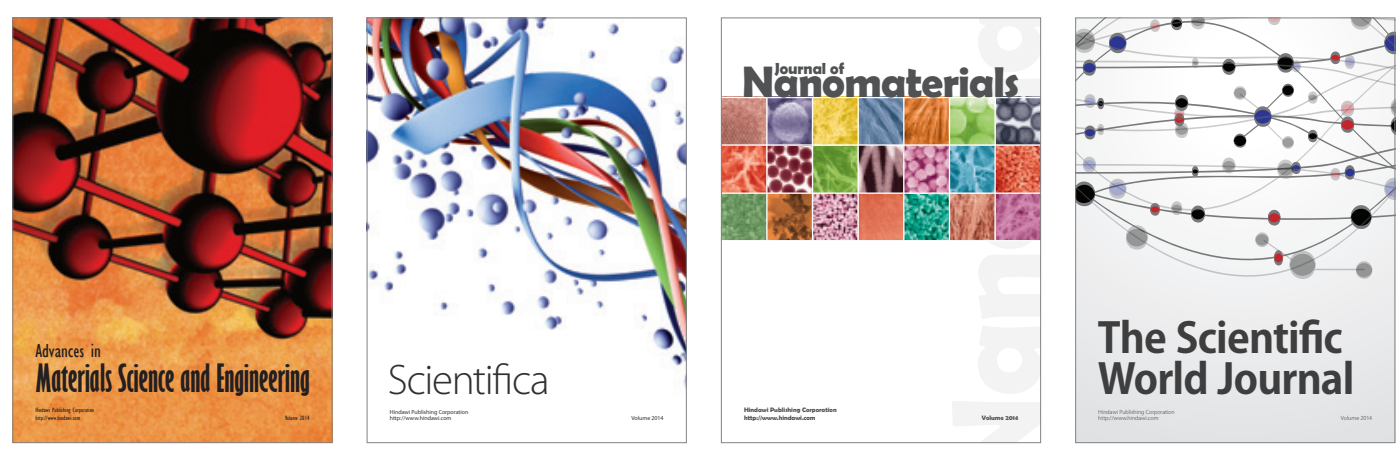

\section{The Scientific World Journal}
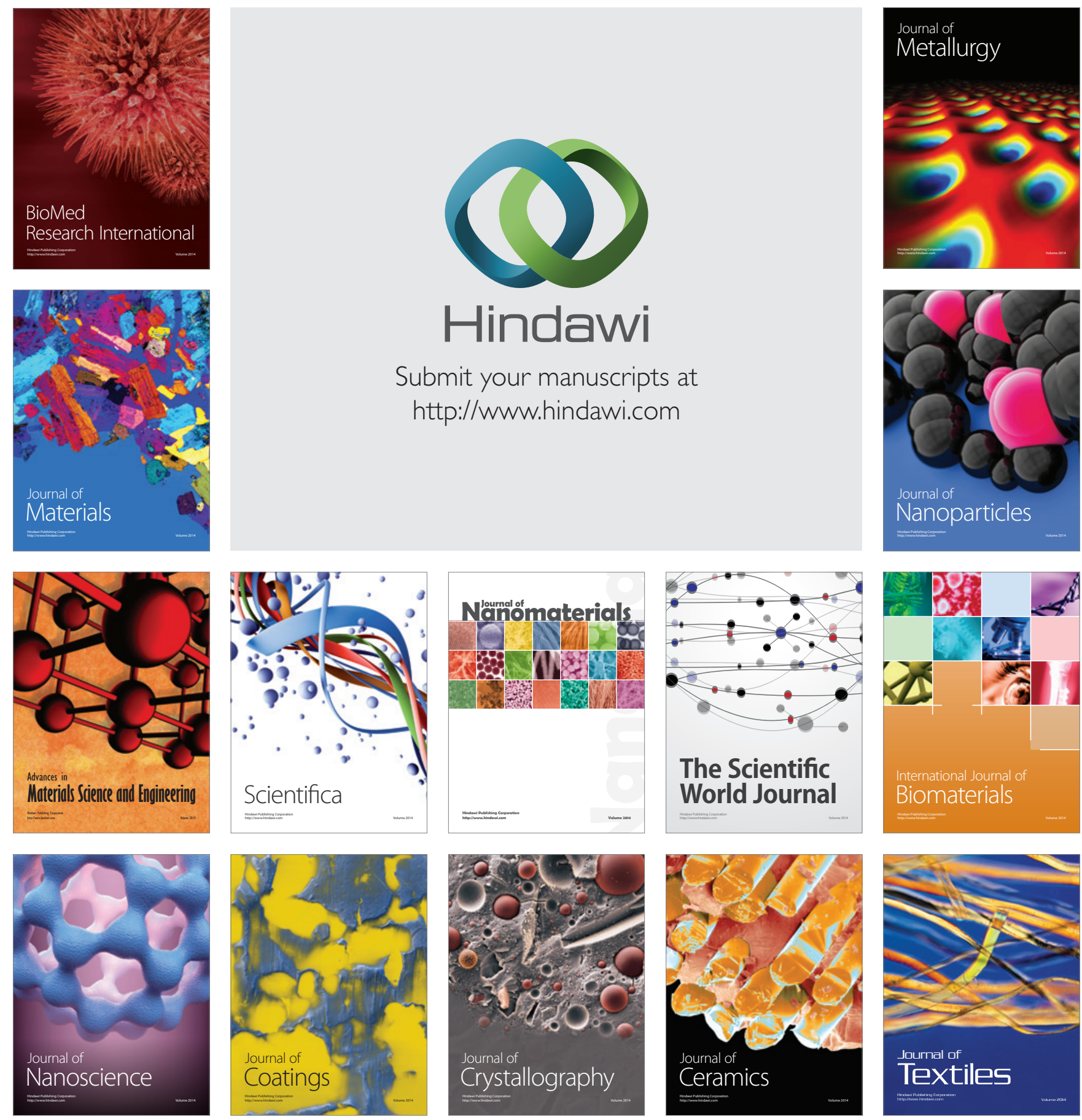